OPEN ACCESS

Edited by:

Yiliang Chen,

Medical College of Wisconsin,

United States

Reviewed by:

Matthieu Ruiz,

Université de Montréal, Canada

Leigh Goedeke,

Yale University, United States

${ }^{*}$ Correspondence:

Loni Berkowitz

loniberko@gmail.com

Specialty section:

This article was submitted to Lipids in Cardiovascular Disease,

a section of the journal

Frontiers in Cardiovascular Medicine

Received: 28 September 2021

Accepted: 21 December 2021

Published: 14 January 2022

Citation:

Berkowitz L, Cabrera-Reyes F

Salazar $C$, Ryff $C D$, Coe $C$ and

Rigotti A (2022) Sphingolipid Profiling:

A Promising Tool for Stratifying the

Metabolic Syndrome-Associated Risk.

Front. Cardiovasc. Med. 8:785124.

doi: $10.3389 /$ fcrm.2021.785124

\section{Sphingolipid Profiling: A Promising Tool for Stratifying the Metabolic Syndrome-Associated Risk}

\author{
Loni Berkowitz ${ }^{1 \star}$, Fernanda Cabrera-Reyes ${ }^{2}$, Cristian Salazar ${ }^{1}$, Carol D. Ryff ${ }^{3}$, \\ Christopher $\mathrm{Coe}^{3}$ and Attilio Rigotti ${ }^{1}$
}

${ }^{1}$ Department of Nutrition, Diabetes and Metabolism \& Center of Molecular Nutrition and Chronic Diseases, School of Medicine, Pontificia Universidad Católica de Chile, Santiago, Chile, ${ }^{2}$ Department of Gastroenterology, School of Medicine, Pontificia Universidad Católica de Chile, Santiago, Chile, ${ }^{3}$ Institute on Aging, University of Wisconsin-Madison, Madison, WI, United States

Metabolic syndrome (MetS) is a multicomponent risk condition that reflects the clustering of individual cardiometabolic risk factors related to abdominal obesity and insulin resistance. MetS increases the risk for cardiovascular diseases (CVD) and type 2 diabetes mellitus (T2DM). However, there still is not total clinical consensus about the definition of MetS, and its pathophysiology seems to be heterogeneous. Moreover, it remains unclear whether MetS is a single syndrome or a set of diverse clinical conditions conferring different metabolic and cardiovascular risks. Indeed, traditional biomarkers alone do not explain well such heterogeneity or the risk of associated diseases. There is thus a need to identify additional biomarkers that may contribute to a better understanding of MetS, along with more accurate prognosis of its various chronic disease risks. To fulfill this need, omics technologies may offer new insights into associations between sphingolipids and cardiometabolic diseases. Particularly, ceramides -the most widely studied sphingolipid class- have been shown to play a causative role in both T2DM and CVD. However, the involvement of simple glycosphingolipids remains controversial. This review focuses on the current understanding of MetS heterogeneity and discuss recent findings to address how sphingolipid profiling can be applied to better characterize MetS-associated risks.

Keywords: sphingolipids, cardiovascular risk (CVD), ceramides, metabolic syndrome, type 2 diabetes

\section{INTRODUCTION}

Cardiovascular diseases (CVD) are currently a major cause of morbidity and mortality with major overall economic healthcare burden worldwide (1). Among these conditions, CVD of atherosclerotic origin (ASCVD) stands out because of its high prevalence and the significant acute ischemic complications and chronic consequences. Many risk factors for ASCVD are wellestablished, including family history, obesity, blood hypertension, dyslipidemia, type 2 diabetes (T2DM), and proinflammatory pathophysiology (2). In particular, metabolic syndrome (MetS) a well-known clustering of risk factors (3)- doubles the risk for CVD and increases five-fold the chance for T2DM (4). Indeed, 13.3 to $44 \%$ of excess CVD mortality in the US is explained by MetS or MetS-related CVD (5). Furthermore, MetS is associated with increased risk of a number of common cancers (6) and neurodegenerative disorders (7) and is also an important risk factor influencing progression and prognosis of COVID-19 (8). 
Based on NHANES reports, the overall prevalence of MetS in US adults was $34.7 \%$ in 2016, increasing with age and reaching $48.6 \%$ among those aged at least 60 years. Remarkably, over 2011-2016, MetS prevalence increased significantly among those aged 20 to 39 years from 16.2 to $21.3 \%$ (9). Thus, prevention, early diagnosis, and appropriate risk stratification of MetS constitute a major health priority challenge. However, besides the many components and clinical implications of MetS, there is no agreement upon clinical definition of MetS. Moreover, the pathophysiology of MetS is not consensual (10), and traditional biomarkers alone do not explain its heterogeneity or the specific risk of associated chronic diseases.

In search for new biomarkers, and in line with the refinement of new omics technologies, several studies have focused on bioactive sphingolipids (SPLs) (11). SPLs have emerged as signaling molecules that regulate many metabolic functions, and ample evidence highlights their role in the regulation of inflammatory responses (12). A substantial body of literature shows that ceramides, a major key class of this lipid family, may have a causative role in diabetes and ASCVD (13). However, the involvement of more simple glycosphingolipids (e.g., hexosylceramides and lactosylceramides) is still controversial.

This review focuses on the current understanding of MetS heterogeneity as well as recent findings that address how sphingolipid profiling may provide additional and valuable information to better characterize MetS-associated risk.

\section{Emerging Cardiovascular Risk Factors, Including Sphingolipid Biomarkers}

There are now many clinical guidelines for evaluation and management of ASCVD risk. The most common factors included in current risk calculators are age, sex, total cholesterol and HDL cholesterol (HDL-c) levels, blood pressure, diabetes, and smoking (14). Some guidelines also add in LDL cholesterol (LDLc) levels, obesity, and high sensitivity C-reactive protein (15). However, there continue to be deficiencies in modeling risk as well as differences in the impact of each component (14). Indeed, estimations indicate that traditional risk algorithms may miss up to $20 \%$ of future CVD events (16).

The pursuit of better strategies for risk prognosis is under continuous evolution. For instance, although plasma LDL-c levels have been considered a primary etiopathogenic factor for development of ASCVD, currently the concentration of nonHDL-c is considered a better predictor of future CVD events (14, 17). Similarly, apolipoprotein B (Apo B) -the structural protein present in all atherogenic lipoproteins- and lipoprotein(a) have also been proposed as emerging cardiovascular risk factors. On the other hand, the recognition of ASCVD as an active process of vascular damage -rather than passive cholesterol infiltration of blood vessels- has highlighted inflammatory and procoagulant mechanisms and biomarkers. In this context, several proinflammatory and prothrombotic molecules (i.e., Creactive protein, fibrinogen, IL-6, sICAM, etc.) are being assessed to add predictive power to existing CVD risk models $(18,19)$.

Currently, some of the most promising CVD risk prediction approaches are panels of multiple circulating biomarkers. In fact, omics technologies have provided new insights into the association between a wide variety of novel plasma molecules and cardiometabolic disorders (20). Particularly, based on the technological advances in lipidomics, researchers have identified nontraditional and less abundant lipids as possible biomarkers of early stage cardiometabolic dysfunction as well as cardiometabolic risk $(21,22)$. Indeed, multiple studies have identified non-traditional lipid species or lipidomic profiles related to subclinical atherosclerosis (23), future cardiovascular events (24-27), and CVD mortality (28). Most of them improved prediction of CVD beyond the sensitivity of traditional cardiovascular risk factors.

Moreover, longitudinal lipidomic phenotypes seem better predictor of future risk of ASCVD in healthy adults. One study showed that numerous non-cholesterol lipids, especially sphingolipid, phospholipid, diacylglycerol, and triglyceride species, deserved more consideration in CVD risk stratification in patients with low-risk cholesterol profiles (29). Similarly, two additional classes of circulating lipids (e.g., dihydroceramides and lysophosphatydilinositol) may serve as novel biomarkers to identify individuals at high-risk of diabetes prior to disease onset (30). In this context, a substantial body of evidence shows that some species of ceramides, a key class of the sphingolipid family, may play a causative role and be relevant for risk prediction of various cardiometabolic disorders, including CVD and diabetes (31-33). These observations have increased the pathophysiological interest and diagnostic potential of sphingolipids in MetS, a condition where the risk of CVD and diabetes converge, but with a highly heterogeneous pathobiology.

\section{MetS Controversies in Definition and Chronic Disease Risk Association}

MetS is a multicomponent condition that reflects the clustering of individual cardiometabolic risk factors related to abdominal obesity and insulin resistance. There are various definitionsbased on shared elements-that somewhat have been agreed upon by different international organizations and expert groups.

A number of the most commonly used definitions are those proposed by the World Health Organization (WHO), the European Group for the Study of Insulin Resistance (EGIR), the National Cholesterol Education Program Adult Treatment Panel III (NCEP:ATPIII), the American Association of Clinical Endocrinology (AACE) and the International Diabetes Federation (IDF) (34). Most organizations recommend a harmonized definition for MetS based on the presence of any 3 of the following 5 risk factors: abdominal obesity, low HDL-c levels, high triglycerides levels, high blood pressure, and hyperglycemia (35). This delineation is congruent with the criteria outlined by the NCEP-ATPIII, one of the most popular definitions of MetS. The IDF definition has the same criteria but considers abdominal obesity as a requirement for MetS diagnosis. Conversely, AACE, $\mathrm{WHO}$, and EGIR definitions regard insulin resistance as central to the pathophysiology of MetS and thus must be present for diagnosis (34).

The need to define MetS more precisely stems from the importance of correctly identifying individuals at high risk 
for ASCVD vs. other chronic diseases. Several epidemiological studies have confirmed the increased risk of ASCVD in individuals with MetS, regardless of the diagnostic criteria used (36-38). However, there continues to be an ongoing controversy about whether MetS is in fact a homogeneous clinical condition, disorder, or disease (39), and whether it requires recognition as a specific syndrome. Moreover, the predictive value of MetS has been questioned because its detection may not provide additional information than its individual components (40). On the other hand, even though MetS has been associated with higher odds of cardiovascular events and T2DM, it remains unclear whether MetS is a single syndrome or a constellation of different attributes or traits conveying a divergent range of metabolic vs. cardiovascular risk (39). Using a continuous MetS severity scale, a study confirmed that a more severe presentation of this syndrome quadruples the risk of coronary events (41). But there are likely to be differences in the associated risk depending on the presence of specific MetS components as well other factors that remain to be defined. For instance, the combination of central obesity, elevated blood pressure, and hyperglycemia conferred the greatest risk for CVD and mortality in the Framingham Offspring Study (42). However, there is a lack of biomarkers that allow a more accurate prediction of a patient's risk progressing to one of the various pathologies associated with MetS (i.e., T2DM, CVD, Alzheimer's disease, cancer).

Traditional serum lipid biomarkers of cardiovascular health include low triglycerides as well as high HDL-c and low LDL-c (2). However, patients with MetS show several lipid abnormalities beyond high LDL-c, elevated triglycerides, or low HDL-c, such as high levels of modified LDL particles (43). In fact, traditional lipid measures alone do not fully explain the complexity of the altered lipid metabolism associated with MetS or its related high cardiovascular risk (CVR) (43). Moreover, currently used risk prediction calculators and available therapies are insufficient and a significant amount of undefined residual CVR remains undetected and untreated (44). In this context, biomarkers beyond those included in the existing definitions of MetS, such as endothelial dysfunction, prothrombotic tendency, and proinflammatory state, may be essential determinants of future CVR in MetS patients (45). However, these risk biomarkers would not provide information regarding the underlying metabolic status, and the risk of other pathologies such as T2DM. As described below, profiling of circulating sphingolipids could contribute to a better pathophysiological understanding of MetS, with more accurate prognosis of cardiovascular vs. diabetic risks.

\section{Sphingolipids}

Sphingolipids (SPL) are a highly diverse group of biomolecules that are not just structural components of cell membranes, but also participate in intra- and extracellular signaling. SPL are found in a wide variety of organisms and are as a matter of fact involved in many aspects of cell structure, recognition, metabolism, and regulation (46).

SPL comprise a complex family of compounds structurally defined by a backbone called "sphingoid" base, mostly represented by sphingosine, which is amide-linked with long- or very-long-chain fatty acids to form ceramides
(Figure 1). Ceramides can be further derivatized -by addition of a headgroup- to form more complex SPL classes, such as sphingomyelin, simple glycosphingolipids (e.g., glucosylceramides, galactosylceramides and lactosylceramides), and more complex glycosphingolipids with a few to dozens of sugar residues, called gangliosides (46). Within each SPL class, there are many species components defined by structural and chemical features (i.e., carbon chain length, double bonds) of the attached fatty acid.

At a cellular level, SPL are found mainly in the plasma membrane, where they interact with cholesterol forming membrane microdomains known as "lipid rafts", which regulate signal transduction and cell recognition. In circulation, $>500$ species of plasma SPLs are transported in the different classes of lipoproteins (i.e., VLDL, LDL, HDL) or associated with albumin $(47,48)$. Lipoprotein-associated SPL can be incorporated into these lipid particles before they are secreted from cells (49), transferred from one lipoprotein to another, or modified within them (47). Consequently, changes in circulating lipoprotein levels may affect circulating sphingolipid levels (48, 50-53).

\section{SPL Profile and Metabolic Complexity}

SPL metabolism can be thought of as a discrete set of three metabolically connected pathways: (a) de novo synthesis coming from saturated fatty acids, (b) salvage of sphingosine, and (c) breakdown of complex SPLs (46), all of which converge into ceramides (Figure 1). In de novo synthesis, an acylCoA condensates with serine, which -by addition of another fatty acid- subsequently gives rise to dihydrosphingosine. Then, sequential enzymatic reactions lead to the generation of dihydroceramide, the reduced precursor of ceramides. Some dihydroceramides are not transformed further and they per se participate in signaling pathways while another fraction is oxidized into ceramides $(46,54)$. Afterwards, ceramides can be modified by incorporation of a polar group, such as phosphocholine, originating sphingomyelin, or sugars, giving rise to a wide range of glycosphingolipids (a.k.a. glycoceramides).

Many glycosyltransferases are involved in the synthesis of glycosphingolipids, starting with the addition of glucose or galactose, leading to the so-called hexosylceramides. Within these, glucosylceramide is the major form, and it may be subsequently modified by lactosylceramide synthase, which adds galactose giving rise to lactosylceramide $(46,55)$. Hexosylceramides and lactosylceramides are simple $\beta$ glycosphingolipids that can be further glycosylated, generating more complex glycosphingolipids (e.g., gangliosides), or remain as such leading to their biological activities (56).

SPL metabolism is interconnected with pathways involved in oxygen biology, immune response, glycolysis, amino acid metabolism, and metabolism of other lipids (46). Hence, there are multiple factors that potentially modify the SPL profile. For example, increases in reactive oxygen species (57) or a hypoxic state (58) predispose to accumulation of dihydroceramides. On the other hand, high levels of circulating saturated fatty acids stimulate a dose-dependent synthesis of ceramides (13, 59), which accounts for the accumulation of ceramides in overnutrition or dyslipidemia (50). Similarly, proinflammatory 


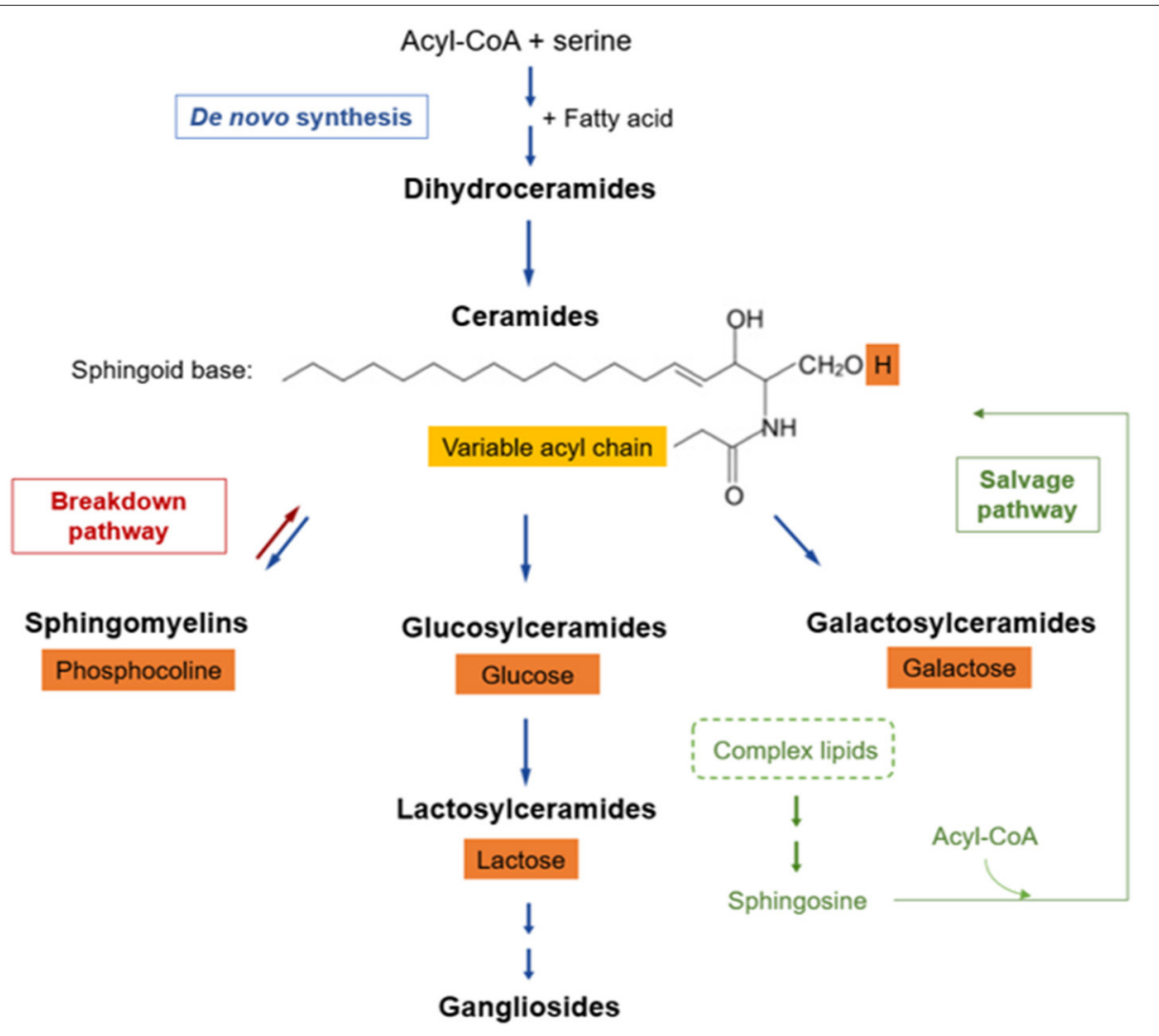

FIGURE 1 | Sphingolipid metabolic pathway. SPLs have three major metabolic pathways, all of which converge into ceramides: (a) de novo synthesis coming from saturated fatty acids, (b) breakdown pathway in which sphingomyelin loses its phosphocholine headgroup, and (c) salvage pathway that allows sphingosine recycling from complex SPLs. The fatty acid (light orange box) defines SPL species, whereas the headgroup (dark orange boxes) defines the SPL class.

cytokines, such as TNF- $\alpha$, can stimulate the hydrolysis of sphingomyelin to ceramide (60), while bacterial antigens (e.g., LPS) promote the synthesis of some glycosphingolipids (61). Both LPS and saturated fatty acids also activate the tolllike receptor 4 (TLR4) and induce the transcription of genes associated with SPL synthesis (61). More distant modulating factors, such as lower psychological well-being, which is linked with an unhealthy lifestyle, has also been associated with higher levels of ceramides (62). Taken together, these findings show that SPL circulate in a dynamic balance that is likely to be altered under various physiological and disease conditions.

\section{Biological Functions of SPLs Related With Cardiometabolic Diseases}

Bioactive lipids are functionally defined as those lipid species whose levels respond to the action of specific stimuli and then regulate distinctive downstream effectors and targets. The most studied bioactive SPLs are ceramides. However, several additional SPL species are being evaluated as potential bioactive lipids (55). Thus, a major challenge is to keep up with the rapid growth in knowledge about the sphingolipidome (i.e., the ensemble of all SPL in living organisms) as well as its physiological and pathogenic impact.
The range of functions currently attributed to bioactive SPLs is wide and includes many aspects of cell biology and body physiology, such as cell growth and cell cycle, cell senescence and death, inflammation, immune response, cell adhesion and migration, angiogenesis, metabolism, and autophagy (55). Considering this wide variety of functions, SPLs have been implicated in several pathological disorders, including obesity, T2DM, atherosclerosis and CVD $(11,63,64)$ (Table 1). However, many of the underlying mechanisms involved remain unclear and vary depending on the specific class, or even species, of SPL. For instance, ceramides elicit metabolic dysfunction by several mechanisms. They inhibit protein kinase $\mathrm{B}(\mathrm{Akt} / \mathrm{PKB})$ via protein phosphatase $2(\mathrm{PP} 2 \mathrm{~A})$ and protein kinase $\mathrm{C}$ zeta $(\mathrm{PKCz})$ intermediaries, which mediate a wide range of downstream effects, including insulin resistance $(55,67,68,93)$. In addition, ceramide acts as a second messenger in activating the apoptotic cascade in many cell types, including $\beta$ cells in pancreatic islets $(33,94)$. Ceramide overload also induces endoplasmic reticulum stress, inhibits mitochondrial fatty acid $\beta$-oxidation, and activates the NLRP3 inflammasome (13), pathophysiological processes associated with obesity.

On the other hand, glycosphingolipids fulfill most of their functions by structuring glycosphingolipid-enriched microdomains in cell membranes. Of particular importance is 
TABLE 1 | Association between sphingolipid classes and cardiometabolic disorders.

\begin{tabular}{|c|c|c|c|c|}
\hline $\begin{array}{l}\text { Sphingolipid } \\
\text { class }\end{array}$ & $\begin{array}{l}\text { Relationship } \\
\text { with }\end{array}$ & Proposed mechanisms & $\begin{array}{l}\text { Most studied SPL } \\
\text { species }\end{array}$ & Supporting evidence \\
\hline & Obesity & & & \\
\hline Ceramides & $\uparrow$ & $\begin{array}{l}\text { Visceral obesity promotes the SPL biosynthetic pathway, } \\
\text { increasing circulating ceramides. }\end{array}$ & Cer-C16 and Cer-C18 & $\begin{array}{l}\text { In vitro and animal models } \\
(61,65,66), \text { cross-sectional } \\
\text { studies (21) }\end{array}$ \\
\hline \multirow[t]{2}{*}{ HexCer/LacCer } & $\downarrow$ or $=$ & Unclear. Upregulation of salvage pathway & $\begin{array}{l}\text { Sphingosine-based } \\
\text { HexCer and Hex2Cer } \\
\text { species }\end{array}$ & $\begin{array}{l}\text { In vitro (49), cross-sectional } \\
\text { studies (21) }\end{array}$ \\
\hline & Dyslipidemia & & & \\
\hline Ceramides & $\begin{array}{l}\uparrow c-L D L, \uparrow T G s, \\
\downarrow c-H D L\end{array}$ & $\begin{array}{l}\text { Bidirectional. Higher levels of ApoB-containing } \\
\text { lipoproteins increase ceramide circulation. } \\
\text { Ceramide depletion could accelerate the catabolism of } \\
\text { ApoB-containing lipoproteins. }\end{array}$ & - & $\begin{array}{l}\text { In vitro (48), animal models } \\
(50), \text { cross-sectional studies } \\
(21,51), \text { prospective studies } \\
(52)\end{array}$ \\
\hline \multirow[t]{2}{*}{ HexCer/LacCer } & $\begin{array}{l}\downarrow c-L D L, \downarrow T G s, \\
\uparrow c-H D L\end{array}$ & Unclear. Upregulation of salvage pathway & & $\begin{array}{l}\text { In vitro (53), cross-sectional } \\
\text { studies (21) }\end{array}$ \\
\hline & Dysglycemia & & & \\
\hline Ceramides & $\uparrow$ & $\begin{array}{l}\text { Ceramide accumulation would alter glucose metabolism, } \\
\text { by inhibition of Akt/PKB, inducing insulin resistance, and } \\
\text { by stimulation of } \beta \text { cells apoptosis in pancreatic islets, } \\
\text { increasing the risk of diabetes. }\end{array}$ & Cer-C18 and C20 & $\begin{array}{l}\text { In vitro (67-69), animal } \\
\text { models (70-72), } \\
\text { cross-sectional studies }(73) \text {, } \\
\text { prospective studies }(21,64)\end{array}$ \\
\hline HexCer/LacCer & $\downarrow$ & $\begin{array}{l}\text { Increased synthesis of hexosylceramides at expense of } \\
\text { ceramides would enhance insulin sensitivity by ceramide } \\
\text { reduction, and by immunomodulatory actions. }\end{array}$ & & $\begin{array}{l}\text { In vitro }(69), \text { animal models } \\
(74,75), \text { cross-sectional } \\
\text { studies }(21), \text { prospective } \\
\text { studies (74-76) }\end{array}$ \\
\hline \multirow[t]{2}{*}{ GM3 } & $\uparrow$ & $\begin{array}{l}\text { GM3 would cause insulin resistance, by reduction of } \\
\text { insulin receptor presentation on fat cell surface due to } \\
\text { changes in composition of lipid rafts. }\end{array}$ & & In vitro and in vivo (77) \\
\hline & $\begin{array}{l}\text { Cardiovascular } \\
\text { disease }\end{array}$ & & & \\
\hline Ceramides & $\uparrow$ & $\begin{array}{l}\text { Ceramides increase CV risk, by increasing transport, } \\
\text { retention, and aggregation of ceramide-enriched LDL } \\
\text { within the vascular wall; apoptosis of cells lining the } \\
\text { vascular wall, and reduction of vasorelaxation and } \\
\text { fibrinolysis. }\end{array}$ & $\begin{array}{l}\text { Cer-C16, C18 and } \\
\text { C24: } 1 \text { and their ratio } \\
\text { over Cer-C24 }\end{array}$ & $\begin{array}{l}\text { In vitro }(14,78), \text { animal } \\
\text { models }(79,80), \text { and } \\
\text { prospective studies }(81-84)\end{array}$ \\
\hline HexCer & $\uparrow$ & $\begin{array}{l}\text { GluCer regulate downstream signaling of LPS/TLR4, } \\
\text { increasing secretion of proinflammatory cytokines. }\end{array}$ & & In vitro $(85,86)$ \\
\hline LacCer & $\uparrow$ & $\begin{array}{l}\text { LacCer increase CV risk: lead to oxidative stress } \\
\text { environment and upregulate adhesion molecules on } \\
\text { vascular endothelial cells and monocytes. }\end{array}$ & & $\begin{array}{l}\text { In vitro }(87-90) \text {, animal } \\
\text { models }(91), \text { prospective } \\
\text { studies }(22,24)\end{array}$ \\
\hline GM3 & $\uparrow$ & GM3 would increase foam cell formation & & In vitro (92) \\
\hline
\end{tabular}

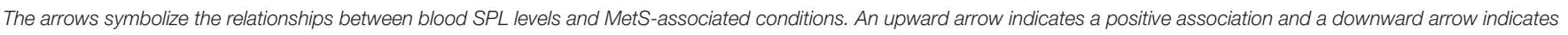
a negative association.

the assembly of these glycosphingolipids with signal transducers and other membrane proteins to form functional signaling units (95). For example, studies showed that GM3, a complex ganglioside, reduced insulin receptor presentation on the cell surface of adipocytes by modifying the composition of lipid rafts (77). However, this alteration in insulin signaling does not occur with simpler glycosphingolipids or in other types of cells, where the effect could even be favorable (69).

In the same line, glycosphingolipids are important determinants of a functional immune system. Glycosphingolipid repertoires present in the plasma membrane of immune cells impact membrane organization, molecular signaling, cell differentiation, and trans-interaction between biomolecules located in adjacent cell surfaces (96). Glycosphingolipid-enriched plasma membrane microdomains mediate immunological and inflammatory reactions, including superoxide generation, chemotaxis, and non-opsonic phagocytosis (97). In addition, lactosylceramides activate cytosolic phospholipase A2 (cPLA2), which cleaves arachidonic acid from phosphatidylcholine to generate eicosanoids and prostaglandins, two essential inflammatory intermediaries $(87,98)$. As detailed below, the role of glycosphingolipids in inflammation and immune response has been directly related to the development and progression of ASCVD.

All these findings have increased interest in verifying the usefulness of measuring plasma SPL levels as new biomarkers. 
However, these analyses have been hampered by the complexity and diverse functions of this lipid family. Therefore, it remains a significant need to better define sphingolipidome profiles under normal and pathological conditions to further understand how absolute levels of different SPLs and, eventually, the relative ratio between them regulate cell function/body physiology and are associated with the origin and progression of chronic diseases. In fact, we must establish more precisely the relevance of SPL profiles to risk stratification and prognosis of MetS, where all the metabolic disorders mentioned above converge.

\section{SPLs as Potential Mediators of Inflammation in Cardiometabolic Diseases Studies in vitro, Cultured Cells, and Animal Models}

Given their role in metabolic and inflammatory processes, there is an emerging interest in elucidating the association of SPLs and ASCVD. Ceramides have been shown to be relevant for understanding the pathophysiology of the atherothrombotic process and exert several specific actions during plaque formation and ischemic complications $(79,80)$ (Table 1). For example, generation of ceramide by sphingomyelinbreakdown induction was found to be sufficient in activating the aggregation of lipoproteins in vitro $(99,100)$. In fact, aggregated LDL particles obtained from atherosclerotic lesions have 10- to 50-fold higher levels of ceramides than plasma LDL particles (101). Ceramide was also implicated in transcytosis of oxidized LDL across endothelial cells, thus leading to the transport and retention of atherogenic lipoproteins within the vascular wall (102). Likewise, the acute induction of ceramide synthesis by monocytes increased adhesion of these proatherogenic lipoproteins to rat aortic endothelium and uptake of oxidized LDL in vitro (103). Moreover, ceramides have been shown to induce apoptosis of cells lining the vascular wall, a process implicated in plaque rupture during acute ischemic complications of atherothrombotic disease (78). Finally, ceramides impair endothelium-dependent vasorelaxation and fibrinolysis in vitro (13) further increasing the risk for atherothrombotic events. In parallel, several studies using cell and animal models have also shown that ceramides impair glucose metabolism in different cell types and organs, including pancreas, skeletal muscle, and adipose tissue $(33,70-72,104$, 105), increasing T2DM risk (64)-a prime risk factor for ASCVD.

In contrast to unglycosylated ceramides, the involvement of glycosphingolipids in cardiometabolic diseases is more controversial. Specifically, simple -rather than complexglycosphingolipids seem to have a protective role against metabolic disorders (Table 1). For example, administration of simple $\beta$-glycosphingolipids showed remarkable beneficial effects on glucose intolerance and hepatic steatosis in mice (74), rats (75), and Psammomys obesus (76). This effect was attributed to the immunomodulatory role of this $\beta$-glycosphingolipid on immune cells involved in these disorders (74-76). As well, induction of glucosylceramide synthesis in myotubes enhanced insulin signaling (69).

In contrast, elevated levels of lactosylceramide -which were accompanied with decreased respiration and calcium retention capacity in mitochondria- have been reported in heart tissue of streptozotocin-induced type 1 diabetes mouse model (106). These metabolic changes may impair immune cell function (107). In addition, lactosylceramides lead to oxidative stress environment in human aortic smooth muscle cells by activating NADPH oxidase and generating reactive oxygen species (108). Therefore, despite the beneficial effects that these glycosphingolipids may have on glucose metabolism, lactosylceramides would contribute to mitochondrial dysfunction, oxidative stress, and inflammatory response in diabetes.

In addition, the involvement of lactosylceramides and hexosylceramides on ASCVD has been reported in several models (Table 1). For example, atherogenic apoE knockout mice exhibit increased serum concentrations of glycosphingolipids and accumulation of specific glycosphingolipids in atherosclerosis-prone regions of the aorta $(91,109)$. In keeping with this finding, using cell lines and mouse models, several immune mechanisms-as follows-have been proposed to account for a direct proatherogenic effect of specific glycosphingolipids. A recent study reported that macrophages accumulated ceramides and glucosylceramide in response to inflammatory activation with IFN- $\gamma$ and LPS (110). Interestingly, glucosylceramide present in plasma membrane microdomains regulate LPS/TLR4 orientation, affecting downstream signaling proteins of this complex and the production of proinflammatory cytokines, as IL- 6 and TNF- $\alpha(85,86)$. On the other hand, lactosylceramide induced smooth muscle cell proliferation in vitro (88) while ganglioside GM3 markedly accelerated LDL uptake by macrophages, leading to generation of lipidladen foam cells (92). On the other hand, in vitro studies, evaluating the pro-inflammatory role of $\beta$-glycosphingolipids, suggested that lactosylceramides may upregulate adhesion molecules on vascular endothelial cells and monocytes as well as activate neutrophils, contributing to atheromatous plaque inflammation $(87,89,90)$. Moreover, a murine model showed that lactosylceramide is enriched in plasma membrane microdomains of neutrophils and involved in cell migration and phagocytosis (97). Indeed, inhibition of glycosphingolipid synthesis helped to preserve cardiac function in an animal model of diet-induced ASCVD (111).

On the other hand, peripheral monocytes isolated from healthy humans exhibited enhanced migration when incubated with exogenous lactosylceramide (112). Specifically, lactosylceramides increased the expression of ICAM-1 in human endothelial cells, through NADPH oxidase activation and ROS generation (113). Similarly, lactosylceramides induced the expression of $\mathrm{CD} 11 / \mathrm{CD} 18$ in human neutrophils and monocytes, facilitating their adhesion to the endothelium and entry into the intimal space $(87,98)$. All these lactosylceramideassociated processes would contribute to inflammation and development of atherosclerosis. Finally, glycosphingolipids can also modulate the adaptative immune response in ASCVD. IFN$\alpha$, a proinflammatory cytokine found in atherosclerotic plaques, upregulated lactosylceramide and glucosylceramide production in mouse B cells (114). These lipid classes are a fundamental component of glycosphingolipid-enriched microdomains 
involved in activation and proliferation of B and T lymphocytes, which modulate and regulate amplification of an inflammatory response (96).

\section{Human Clinical and Epidemiological Studies}

More recently, several studies in humans have shown an association between ceramides and cardiometabolic diseases. High levels of plasma ceramides were detected in patients with T2DM (33), arterial hypertension (115), and atherosclerosis (116). Furthermore, accumulation of ceramides in atheromatous plaques seems to stimulate apoptosis of vascular cells, destabilizing the plaque, and thus favoring acute ischemic events $(14,78)$. In agreement with this perspective, multiple studies have confirmed the association between ceramides and cardiovascular events, even after adjusting for all other well-known risk factors (81-84).

Among the ceramide species studied in humans, whereas Cer-C18 and C20 have been the most associated with T2DM, Cer-C16, C18 and C24:1 as well as their ratio over Cer-C24 have been the species mainly correlated with $\operatorname{CVD}(11,73)$ (Table 1). Based on this type of evidence, a blood ceramide-based diagnostic CVR test (Ceramide Risk Score) was commercialized in 2016 (117). However, one limitation when interpreting the results from this test is that ceramides may be raised in response to different inflammatory states, which are not necessarily indicative of ASCVD (117). Moreover, basal SPL levels also evince considerable variation across different racial and ethnic populations (118). Therefore, more basic and clinical research is still required to further characterize SPL profiles before they can be employed as a diagnostic test with high sensitivity and specificity in routine medical practice.

As mentioned above, the relationship between glycosphingolipids and abnormal cardiometabolic processes remain controversial, but as this article explains, it seems dependent on the pathophysiological context. For example, three recent studies-based on different methodologies and populations-found a negative correlation between hexosylceramide levels and clinical and biochemical features of obesity and diabetes $(21,119,120)$. Furthermore, a negative association between simple $\beta$-glycosphingolipids and the diagnosis of T2DM was found during follow-up (21). Interestingly, these observations have not been limited to only a few molecular forms, but to multiple species of hexosylceramides and lactosylceramides $(21,119,120)$. In sum, emerging evidence seems to indicate that low circulating levels of simple $\beta$-glycosphingolipids and high levels of ceramides (i.e., high ceramide/simple $\beta$-glycosphingolipids ratio) would be consistently associated with glucometabolic disorders.

Conversely, in the last years, two large prospective cohortbased studies of lipidomic profiles positively associated both ceramides and simple $\beta$-glycosphingolipids with future cardiovascular events and cardiovascular death, even in patients with T2DM and after adjusting for traditional risk factors $(22,24)$. Similarly, levels of lactosylceramides, glucosylceramides, and dihydroceramides were directly correlated with levels of macrophages, IL-6, and macrophage inflammatory protein-1 $\beta$ in human carotid plaques (89). Moreover, a strong link between pulse wave velocity and arterial stiffness, as preclinical atherosclerotic biomarkers, with plasma lactosylceramide levels was found in overweight middle-aged subjects who had fasting hyperglycemia (121). Therefore, despite the relationship with better glucose metabolism, all these studies suggest a potential pro-atherogenic role of simple $\beta$-glycosphingolipids, consistent with the aforementioned in vitro studies.

\section{SPLs and MetS Associated-Risk Stratification}

Several lipidomic studies have in fact identified novel biomarkers linked to metabolic syndrome or its components (122-124). However, most of them are cross-sectional studies or consider MetS as a single disorder. To our knowledge, only one study evaluated lipid species associated with longitudinal changes in MetS components (125). Whereas lysophosphatidylcholine species were correlated with lower BMI and glycemia, two sphingomyelin species were associated with an increased blood glucose levels during follow-up. However, it remains unclear if these lipid signatures could indeed predict the future risk of diseases associated to MetS.

As mentioned above, there is a variable, and even divergent, relationship between different sphingolipid classes and cardiometabolic conditions such as dyslipidemia, insulin resistance, obesity, and atherosclerosis (Figure 2). Thus, it seems appropriate to hypothesize that further sphingolipid profile characterization may contribute to a better understanding of a complex clinical condition such as MetS, in which different cardiometabolic alterations converge and progress heterogeneously. However, it should be noted that although various studies relate sphingolipids with specific cardiometabolic alterations, much of its potential as biomarkers is based primarily on cohort association studies. For example, several lipid profiling studies have reported that circulating dihydroceramides were strong prognostic indicators of future glucometabolic dysfunction $(126,127)$. Even so, dihydroceramides would not be causative, but most likely would serve as markers of increased flux of fatty acids due to insulin resistance through the ceramide biosynthetic pathway (70).

Regarding specific components of the MetS definition, the associations of sphingolipids with obesity and insulin resistance have been well characterized in humans and animal models $(13,65,66)$. Overnutrition and visceral obesity promote SPLs synthesis and turnover, which in turn remodels SPLs profiles and their topological distribution within and between cell membranes, thus defining organelle structure and function $(33,54,125)$. In this context, ceramide accumulation in tissues may be impairing many metabolic processes that underlie diabetes and diabetic complications, according to the mechanisms already described (13). Interestingly, Chaurasia et al. demonstrated that inhibition of the enzymatic transformation of dihydroceramides to ceramides in obese mice resolved hepatic steatosis and insulin resistance, 


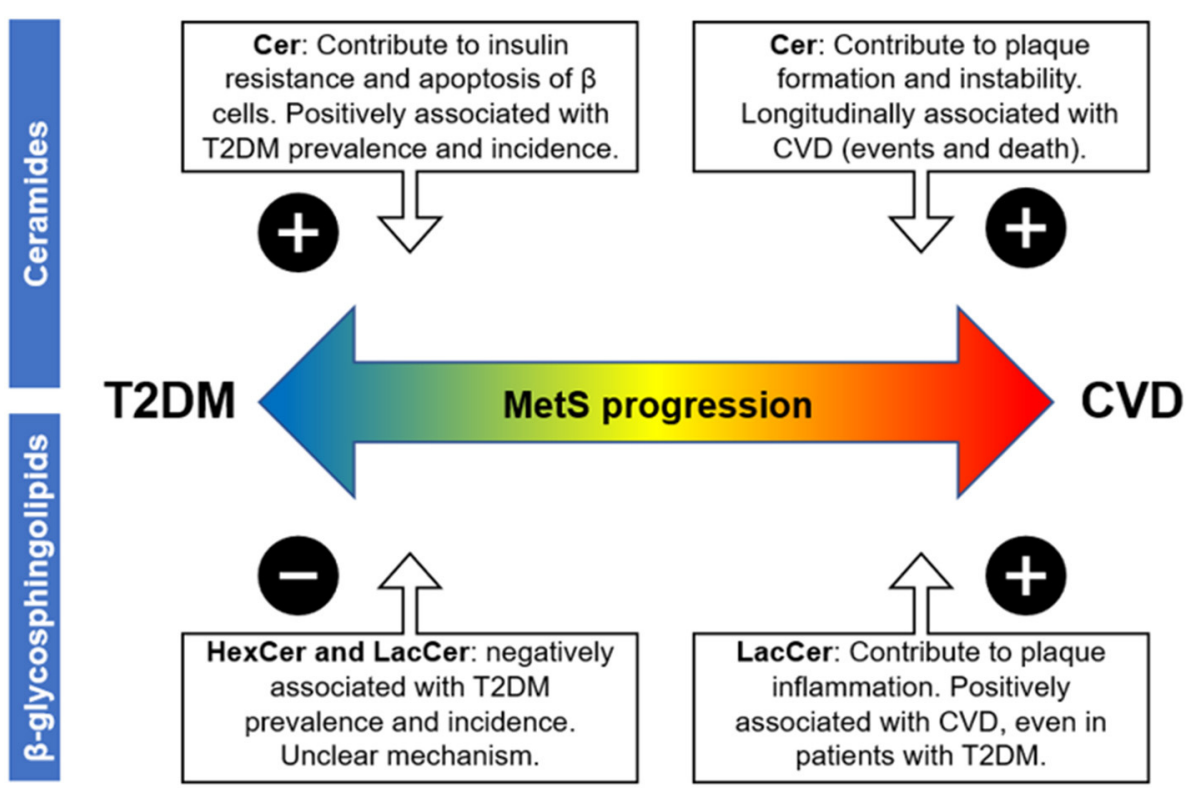

FIGURE 2 | Possible impact of blood sphingolipid profile on MetS-associated cardiovascular vs. metabolic risk based on cross-sectional and longitudinal association studies. Abbreviations are as follows: metabolic syndrome (MetS), atherosclerotic cardiovascular disease (ASCVD), and type 2 diabetes mellitus (T2DM). The "plus sign" denotes a positive association between the respective disease progression and the sphingolipid class, while the minus sign denotes a negative association.

suggesting that ceramide actions could not be recapitulated by dihydroceramides (70).

On the other hand, hexosylceramides and lactosylceramides have an immunomodulatory role, and their overall effect would depend on the overall pathophysiological context. Regarding metabolic risk, several studies have consistently shown an inverse relationship between plasma levels of simple $\beta$ glycosphingolipids and the prevalence and incidence of diabetes, using different methodologies and based on various population cohort $(21,119,120)$. Although the mechanism is not clear, administration of these glycosphingolipids improved glucose intolerance in different animal models of diabetes $(74,75)$, suggesting a causal role. Therefore, in patients with MetS and overweight, high circulating levels of ceramides would increase the risk of diabetes, whereas this risk could be counterbalanced by the concentrations of simple glycosphingolipids.

Conversely, both ceramides and simple $\beta$-glycosphingolipids have been positively associated with ASCVD, as mentioned above. Increased levels of ceramides were related to aggregation of LDL particles in atherosclerotic lesions, induction of apoptosis of cells lining the vascular wall, and platelet activation and aggregation $(100,102,103)$. On the other hand, lactosylceramides may upregulate adhesion molecules on monocytes and vascular endothelial cells as well as activate neutrophils, contributing to plaque inflammation and instability (98). In fact, human studies show that both ceramides and simple $\beta$-glycosphingolipids are associated with the occurrence of cardiovascular events and cardiovascular death, even in patients with T2DM (22). Therefore, despite the beneficial effects that simple $\beta$-glycosphingolipids may have on glucose metabolism and intolerance, both ceramides and simple $\beta$-glycosphingolipids may contribute to cardiovascular risk in patients with MetS.
Interestingly, a recent study showed that statin therapy did not significantly lower circulating concentrations of these two sphingolipids (128). Therefore, high levels of ceramides and glycosphingolipids could account for a fraction of the residual cardiometabolic risk in statin-treated MetS patients.

Based on all this background, SPL profiling may provide novel and relevant insights into the burden of cardio vs. metabolic risk in patients with MetS. Although abdominal obesity seems to increase all classes of sphingolipids, a blood profile characterized by high levels of ceramides and low levels of simple $\beta$ glycosphingolipids in MetS patients may implicate a higher risk of T2DM (Figure 2), based on the evidence discussed here. On the other hand, a profile characterized by high levels of both ceramides and simple $\beta$-glycosphingolipids during MetS could indicate a more inflammatory and pro-atherogenic state, and therefore, a higher risk of ASCVD (Figure 2).

Importantly, careful consideration of experimental procedures and control variables is required during characterization of sphingolipidomes. Some differences can be observed depending on the analytic technique used, the origin of the sample (e.g., serum vs. plasma), and the feeding condition of the subject (e.g., fasting vs. non fasting) $(20,129)$. Furthermore, it is also necessary to evaluate the representativeness of these biomarkers among different subpopulations, since it could vary by racial, sex or age groups $(130,131)$. For example, there are ethnic and racial differences in the prevalence of MetS and its components (132). In general, African-Americans have lower prevalence of MetS when compared to whites, but suffer disproportionately from higher cardiovascular mortality and T2DM (132). Thus, further research is needed to explore the potential applications of SPL profiling to improve MetS-associated risk prediction in this population. 


\section{CONCLUSION}

Stratification and better risk prediction of MetS constitutes a health priority and challenge. Traditional biomarkers alone do not explain its heterogeneity or the specific future risk of associated diseases. Moreover, even though MetS has previously been linked with higher odds of cardiovascular events, little is known about specific clusters of MetS components and their associated-risk differences for development of ASCVD vs. T2DM.

The evidence discussed in this review suggests that sphingolipid profiling appears as a promising tool for MetS-associated risk stratification. Evaluation of simple $\beta$ glycosphingolipids, in addition to more commonly assessed ceramide species, may provide relevant insights into the burden of dysmetabolic state vs. inflammatory state in patients with MetS. Based on this information, the sphingolipid profile -as an additional laboratory test- may have the potential to greatly improve the ability to distinguish MetS patients at risk of suffering a cardiovascular event in the short/medium term from

\section{REFERENCES}

1. World Health O. Noncommunicable diseases. (2016) Available online at: https://www.who.int/news-room/fact-sheets/detail/noncommunicablediseases

2. Benjamin EJ, Virani SS, Callaway CW, Chamberlain AM, Chang AR, Cheng S, et al. Heart disease and stroke statistics -2018 update: a report from the american heart association. Circulation. (2018) 137:e67-e492. doi: 10.1161/CIR.0000000000000558

3. Grundy SM, Brewer HB, Cleeman JI, Smith SC, Lenfant C, American Heart A, et al. Definition of metabolic syndrome: Report of the National Heart, Lung, and Blood Institute/American Heart Association conference on scientific issues related to definition. Circulation. (2004) 109:433-8. doi: 10.1161/01.CIR.0000111245.75752.C6

4. Alberti KGMM, Eckel RH, Grundy SM, Zimmet PZ, Cleeman JI, Donato KA, et al. Harmonizing the metabolic syndrome: a joint interim statement of the International Diabetes Federation Task Force on Epidemiology and Prevention; National Heart, Lung, and Blood Institute; American Heart Association; World Heart Federation; International Atherosclerosis Society; and International Association for the Study of Obesity. Circulation. (2009) 120:1640-5. doi: 10.1161/CIRCULATIONAHA.109.192644

5. Liu L, Miura K, Fujiyoshi A, Kadota A, Miyagawa N, Nakamura Y, et al. Impact of metabolic syndrome on the risk of cardiovascular disease mortality in the United States and in Japan. Am J Cardiol. (2014) 113:84-9. doi: 10.1016/j.amjcard.2013.08.042

6. Esposito K, Chiodini P, Colao A, Lenzi A, Giugliano D. Metabolic syndrome and risk of cancer: A systematic review and meta-analysis. Diabetes Care. (2012) 35:2402-11. doi: 10.2337/dc12-0336

7. Borshchev YY, Uspensky YP, Galagudza MM. Pathogenetic pathways of cognitive dysfunction and dementia in metabolic syndrome. Elsevier Inc. (2019). doi: 10.1016/j.lfs.2019.116932

8. Costa FF, Rosário WR, Ribeiro Farias AC, de Souza RG, Duarte Gondim RS, Barroso WA. Metabolic syndrome and COVID-19: An update on the associated comorbidities and proposed therapies. Elsevier Ltd. (2020) p. 809-814. doi: 10.1016/j.dsx.2020.06.016

9. Hirode G, Wong RJ. Trends in the prevalence of metabolic syndrome in the United States, 2011-2016. JAMA. (2020) 323:2526-8. doi: 10.1001/jama.2020.4501

10. Bovolini A, Garcia J, Andrade MA, Duarte JA. Metabolic syndrome pathophysiology and predisposing factors. Int J Sports Med. (2020) 42:199214. doi: $10.1055 / \mathrm{a}-1263-0898$ those patients more likely to develop diabetes in the future. We are currently carrying out prospective cohort studies that will be critical to evaluate whether different SPL profiles allow a better classification of MetS patients based on their clinical progression.

\section{AUTHOR CONTRIBUTIONS}

LB and AR: conceptualization. LB, FC-R, CS, and AR: writingoriginal draft preparation. LB, FC-R, CS, CR, CC, and AR: writing-review and editing. All authors contributed to the article and approved the submitted version.

\section{FUNDING}

Preparation of this manuscript was supported by the National Fund of Scientific and Technological Development (Postdoctoral FONDECYT Grant \#3210391 and regular FONDECYT Grant \#1201607) from the Government of Chile and by the National Institute on Aging (Grant \#P01 AG020166).

11. Kurz J, Parnham MJ, Geisslinger G, Schiffmann S. Ceramides as novel disease biomarkers. Trends Mol Med. (2019) 25:20-32. doi: 10.1016/j.molmed.2018.10.009

12. Albi E, Alessenko A, Grösch S. Sphingolipids in Inflammation. Mediators of inflammation. (2018) (2018). doi: 10.1155/2018/7464702

13. Chaurasia B, Summers SA. Ceramides - lipotoxic inducers of metabolic disorders. Trends Endocrinol Metab. (2015) 26:538-50. doi: 10.1016/j.tem.2015.07.006

14. Goff DC, Lloyd-Jones DM, Bennett G, Coady S, D'Agostino RB, Gibbons R, et al. 2013 ACC/AHA guideline on the assessment of cardiovascular risk: a report of the American College of Cardiology/American Heart Association Task Force on Practice Guidelines. J Am Coll Cardiol. (2014) 63:2935-59. doi: 10.1016/j.jacc.2013.11.005

15. Hippisley-Cox J, Coupland C, Vinogradova Y, Robson J, Minhas R, Sheikh A et al. Predicting cardiovascular risk in England and Wales: prospective derivation and validation of QRISK2. BMJ. (2008) 336:1475-82. doi: 10.1136/bmj.39609.449676.25

16. MacNamara J, Eapen DJ, Quyyumi A, Sperling L. Novel biomarkers for cardiovascular risk assessment: current status and future directions. Future Cardiol. (2015) 11:597-613. doi: 10.2217/fca.15.39

17. Mora S, Buring JE, Ridker PM. Discordance of low-density lipoprotein (LDL) cholesterol with alternative LDL-related measures and future coronary events. Circulation. (2014) 129:553-61. doi: 10.1161/CIRCULATIONAHA.113.005873

18. Tzoulaki I, Murray GD, Lee AJ, Rumley A, Lowe GDO, Fowkes FGR. C-reactive protein, interleukin-6, and soluble adhesion molecules as predictors of progressive peripheral atherosclerosis in the general population: Edinburgh artery study. Circulation. (2005) 112:976-83. doi: 10.1161/CIRCULATIONAHA.104.513085

19. Amar J, Fauvel J, Drouet L, Ruidavets JB, Perret B, Chamontin B, et al. Interleukin 6 is associated with subclinical atherosclerosis: a link with soluble intercellular adhesion molecule 1. J Hypertens. (2006) 24:1083-8. doi: 10.1097/01.hjh.0000226198.44181.0c

20. Hinterwirth H, Stegemann C, Mayr M. Lipidomics: quest for molecular lipid biomarkers in cardiovascular disease. Circ Cardiovasc Genet. (2014) 7:941-54. doi: 10.1161/CIRCGENETICS.114.000550

21. Chew WS, Torta F, Ji S, Choi H, Begum H, Sim X, et al. Large-scale lipidomics identifies associations between plasma sphingolipids and T2DM incidence. JCI Insight. (2019) 4. doi: 10.1172/jci.insight.126925

22. Alshehry ZH, Mundra PA, Barlow CK, Mellett NA, Wong G, McConville $\mathrm{MJ}$, et al. Plasma lipidomic profiles improve on traditional risk factors for the 
prediction of cardiovascular events in type 2 diabetes mellitus. Circulation. (2016) 134:1637-50. doi: 10.1161/CIRCULATIONAHA.116.023233

23. Hoong JSY, Chew WS, Torta F, Ji S, Choi H, Begum H, et al. Plasma sphingolipids and subclinical atherosclerosis - novel associations uncovered by a large-scale lipidomic analysis (P18-129-19). Curr Dev Nutr. (2019) 3 . doi: 10.1093/cdn/nzz039.P18-129-19

24. Poss AM, Maschek JA, Cox JE, Hauner BJ, Hopkins PN, Hunt SC, et al. Machine learning reveals serum sphingolipids as cholesterol-independent biomarkers of coronary artery disease. J Clin Invest. (2020) 130:1363-76. doi: $10.1172 /$ JCI131838

25. Ottosson F, Emami Khoonsari P, Gerl MJ, Simons K, Melander O, Fernandez $\mathrm{C}$, et al. plasma lipid signature predicts incident coronary artery disease. Int J Cardiol. (2021) 331:249-54. doi: 10.1016/j.ijcard.2021.01.059

26. Stegemann C, Pechlaner R, Willeit P, Langley SR, Mangino M, Mayr $\mathrm{U}$, et al. Lipidomics profiling and risk of cardiovascular disease in the prospective population-based Bruneck study. Circulation. (2014) 129:182131. doi: 10.1161/CIRCULATIONAHA.113.002500

27. Zhang W, Gong L, Yang S, Lv Y, Han F, Liu H, Liu L. Lipidomics Profile Changes of Type 2 Diabetes Mellitus with Acute Myocardial Infarction. Dis Markers. (2019). 2019. doi: 10.1155/2019/7614715

28. Gencer B, Morrow DA, Braunwald E, Goodrich EL, Hilvo M, Kauhanen D, et al. Plasma ceramide and phospholipid-based risk score and the risk of cardiovascular death in patients after acute coronary syndrome. Eur J Prev Cardiol. (2020). doi: 10.1093/eurjpc/zwaa143

29. Sock-Hwee T, Jing Yi C, Bo B, Ong CC, Yang X, Teo L, et al. Circadian and longitudinal lipidomic phenotypes are associated with presymptomatic coronary artery disease in healthy subjects with low-intermediate risk cholesterol profiles | circulation. Circulation. (2018) 138:A15581.

30. Mousa A, Naderpoor N, Mellett N, Wilson K, Plebanski M, Meikle PJ, et al. Lipidomic profiling reveals early-stage metabolic dysfunction in overweight or obese humans. Biochim Biophys Acta Mol Cell Biol Lipids. (2019) 1864:335-43. doi: 10.1016/j.bbalip.2018.12.014

31. Chaurasia B, Summers SA. Ceramides - lipotoxic inducers of metabolic disorders. Trends Endocrinol Metab. (2018) 29:66-7. doi: 10.1016/j.tem.2017.09.005

32. Sokolowska E, Blachnio-Zabielska A. The role of ceramides in insulin resistance. Front Endocrinol. (2019) 10:577-577. doi: 10.3389/fendo.2019.00577

33. Yaribeygi H, Bo S, Ruscica M, Sahebkar A. Ceramides and diabetes mellitus: an update on the potential molecular relationships. Diabetic Med. (2020) 37:11-9. doi: 10.1111/dme.13943

34. Huang PL, A. comprehensive definition for metabolic syndrome. Dis Model Mech. (2009) 2:231-7. doi: $10.1242 / \mathrm{dmm} .001180$

35. Grundy SM. Metabolic syndrome update. Trends Cardiovasc Med. (2016) 26:364-73. doi: 10.1016/j.tcm.2015.10.004

36. Hunt KJ, Rg R, Williams K, Haffner SM, Stern MP. National Cholesterol Education Program vs. World Health Organization metabolic syndrome in relation to all-cause and cardiovascular mortality in the San Antonio Heart Study. Circulation. (2004) 110:1251-7. doi: 10.1161/01.CIR.0000140762.04598.F9

37. Isomaa $B$, Almgren $P$, Tuomi $T$, Forsén $B$, Lahti $K$, Nissén $M$, et al. Cardiovascular morbidity and mortality associated with the metabolic syndrome. Diabetes Care. (2001) 24:683-9. doi: 10.2337/diacare.24.4.683

38. Lakka HM, Laaksonen DE, Lakka TA, Niskanen LK, Kumpusalo E, Tuomilehto J, et al. The metabolic syndrome and total and cardiovascular disease mortality in middle-aged men. JAMA. (2002) 288:2709-16. doi: 10.1001/jama.288.21.2709

39. Scuteri A, Laurent S, Cucca F, Cockcroft J, Cunha PG, Mañas LR, et al. Metabolic syndrome across Europe: different clusters of risk factors. Eur J Prev Cardiol. (2015) 22:486-91. doi: 10.1177/2047487314525529

40. Gami AS, Witt BJ, Howard DE, Erwin PJ, Gami LA, Somers VK, et al. Metabolic syndrome and risk of incident cardiovascular events and death. A systematic review and meta-analysis of longitudinal studies. J Am Coll Cardiol. (2007) 49:403-14. doi: 10.1016/j.jacc.2006.09.032

41. DeBoer MD, Gurka MJ, Golden SH, Musani SK, Sims M, Vishnu A, et al. Independent Associations Between Metabolic Syndrome Severity and Future Coronary Heart Disease by Sex and Race. J Am Coll Cardiol. (2017) 69:12045. doi: 10.1016/j.jacc.2016.10.088
42. Franco OH, Massaro JM, Civil J, Cobain MR, O'Malley B, D'Agostino RB. Trajectories of entering the metabolic syndrome: the framingham heart study. Circulation. (2009) 120:1943-50. doi: 10.1161/CIRCULATIONAHA.109.855817

43. Paredes S, Fonseca L, Ribeiro L, Ramos H, Oliveira JC, Palma I. Novel and traditional lipid profiles in Metabolic Syndrome reveal a high atherogenicity. Sci Rep. (2019) 9:11792-11792. doi: 10.1038/s41598-019-48120-5

44. Cho KI Yu J, Hayashi T, Han SH, Koh KK. Strategies to overcome residual risk during statins era. Circulation J. (2019). doi: 10.1253/circj.CJ-19-0624

45. Grandl G, Wolfrum C. Hemostasis, endothelial stress, inflammation, and the metabolic syndrome. Semin Immunopathol. (2018) 40:215-24. doi: $10.1007 / \mathrm{s} 00281-017-0666-5$

46. Merrill AH. Sphingolipid and glycosphingolipid metabolic pathways in the era of sphingolipidomics. Chem Rev. (2011) 111:6387-422. doi: $10.1021 / \mathrm{cr} 2002917$

47. Iqbal J, Walsh MT, Hammad SM, Hussain MM. Sphingolipids and lipoproteins in health and metabolic disorders. Trends Endocrinol Metab. (2017) 28:506-18. doi: 10.1016/j.tem.2017.03.005

48. Merrill AH Jr, Lingrell S, Wang E, Nikolova-Karakashian M, Vales TR, Vance DE. Sphingolipid biosynthesis de novo by rat hepatocytes in culture. Ceramide and sphingomyelin are associated with, but not required for, very low density lipoprotein secretion. J Biol Chem. (1995) 270:13834-41. doi: $10.1074 /$ jbc. 270.23 .13834

49. Iqbal J, Walsh MT, Hammad SM, Cuchel M, Tarugi P, Hegele RA, et al. Microsomal triglyceride transfer protein transfers and determines plasma concentrations of ceramide and sphingomyelin but not glycosylceramide. $J$ Biol Chem. (2015) 290:25863-75. doi: 10.1074/jbc.M115.659110

50. Kasumov T, Li L, Li M, Gulshan K, Kirwan JP, Liu X, et al. Ceramide as a mediator of non-alcoholic Fatty liver disease and associated atherosclerosis. PLoS ONE. (2015). 10:e0126910. doi: 10.1371/journal.pone.0126910

51. Heneghan HM, Huang H, Kashyap SR, Gornik HL, McCullough AJ, Schauer PR, et al. Reduced cardiovascular risk after bariatric surgery is linked to plasma ceramides, apolipoprotein-B100, and ApoB100/A1 ratio. Surg Obes Relat Dis. (2013) 9:100-7. doi: 10.1016/j.soard.2011.11.018

52. Ng TW, Ooi EM, Watts GF, Chan DC, Meikle PJ, Barrett PH. Association of plasma ceramides and sphingomyelin with VLDL apoB-100 fractional catabolic rate before and after rosuvastatin treatment. J Clin Endocrinol Metab. (2015) 100:2497-501. doi: 10.1210/jc.2014-4348

53. Wallner S, Grandl M, Liebisch G, Peer M, Orsó E, Sigrüner A, et al. oxLDL and eLDL induced membrane microdomains in human macrophages. PLoS ONE. (2016) 11:e0166798. doi: 10.1371/journal.pone.0166798

54. Castillo RI, Rojo LE, Henriquez-Henriquez M, Silva H, Maturana A, Villar MJ, et al. From molecules to the clinic: linking schizophrenia and metabolic syndrome through sphingolipids metabolism. Front Neurosci. (2016) 10:488-488. doi: 10.3389/fnins.2016.00488

55. Hannun YA, Obeid LM. Sphingolipids and their metabolism in physiology and disease. Nature reviews. Molecular Cell Biology. (2018) 19:175-91. doi: 10.1038/nrm.2017.107

56. Yoshizaki F, Nakayama H, Iwahara C, Takamori K, Ogawa H, Iwabuchi $\mathrm{K}$. Role of glycosphingolipid-enriched microdomains in innate immunity: microdomain-dependent phagocytic cell functions. Biochim Biophys Acta. (2008) 1780:383-92. doi: 10.1016/j.bbagen.2007.11.004

57. Gagliostro V, Casas J, Caretti A, Abad JL, Tagliavacca L, Ghidoni R, et al. Dihydroceramide delays cell cycle G1/S transition via activation of ER stress and induction of autophagy. Int J Biochem Cell Biol. (2012) 44:2135-43. doi: 10.1016/j.biocel.2012.08.025

58. Rao P, Ande A, Sinha N, Kumar A, Kumar S. Effects of cigarette smoke condensate on oxidative stress, apoptotic cell death, and hiv replication in human monocytic cells. PLOS ONE. (2016) 11:e0155791. doi: 10.1371/journal.pone.0155791

59. Reginato A, Veras ACC, Baqueiro MDN, Panzarin C, Siqueira BP, Milanski $\mathrm{M}$, et al. The role of fatty acids in ceramide pathways and their influence on hypothalamic regulation of energy balance: a systematic review. Int J Mol Sci. (2021) 22. doi: 10.3390/ijms22105357

60. Schütze S, Potthoff K, Machleidt T, Berkovic D, Wiegmann K, Krönke $\mathrm{M}$, et al. activates NF-KB by phosphatidylcholine-specific phospholipase C-induced "Acidic" sphingomyelin breakdown. Cell. (1992) 71:765-76. doi: 10.1016/0092-8674(92)90553-O 
61. Holland WL, Bikman BT, Wang L-P, Yuguang G, Sargent KM, Bulchand $\mathrm{S}$, et al. Lipid-induced insulin resistance mediated by the proinflammatory receptor TLR4 requires saturated fatty acid-induced ceramide biosynthesis in mice. J Clin Invest. (2011) 121:1858-70. doi: 10.1172/JCI43378

62. Berkowitz L, Henríquez MP, Salazar C, Rojas E, Echeverría G, Love GD, et al. Association between serum sphingolipids and eudaimonic well-being in white U.S. adults. Sci Rep. (2021) 11:13139. doi: 10.1038/s41598-021-92576-3

63. Cowart LA. Sphingolipids: players in the pathology of metabolic disease. Trends Endocrinol Metab. (2009) 20:34-42. doi: 10.1016/j.tem.2008.09.004

64. Fretts AM, Jensen PN, Hoofnagle A, McKnight B, Howard BV, Umans J, et al. Plasma ceramide species are associated with diabetes risk in participants of the strong heart study. J Nutr. (2020) 150:1214-22. doi: 10.1093/jn/nxz259

65. Raichur S, Brunner B, Bielohuby M, Hansen G, Pfenninger A, Wang B, Bruning JC, Larsen PJ, Tennagels N. The role of C16:0 ceramide in the development of obesity and type 2 diabetes: CerS6 inhibition as a novel therapeutic approach. Mol Metab. (2019) 21:36-50.

66. Newgard CB, An J, Bain JR, Muehlbauer MJ, Stevens RD, Lien LF, et al. A branched-chain amino acid-related metabolic signature that differentiates obese and lean humans and contributes to insulin resistance. Cell Metab. (2009) 9:311-26.

67. Powell DJ, Hajduch E, Kular G, Hundal HS. Ceramide disables 3phosphoinositide binding to the pleckstrin homology domain of protein kinase B (PKB)/Akt by a PKCzeta-dependent mechanism. Mol Cell Biol. (2003) 23:7794-808. doi: 10.1128/MCB.23.21.7794-7808.2003

68. Stratford S, Hoehn KL, Liu F, Summers SA. Regulation of insulin action by ceramide: dual mechanisms linking ceramide accumulation to the inhibition of Akt/protein kinase B. J Biol Chem. (2004) 279:36608-15. doi: 10.1074/jbc.M406499200

69. Chavez JA, Siddique MM, Wang ST, Ching J, Shayman JA, Summers SA. Ceramides and glucosylceramides are independent antagonists of insulin signaling. J Biol Chem. (2014) 289:723-34. doi: 10.1074/jbc.M113.522847

70. Chaurasia B, Tippetts T, Monibas R, Liu J, Li Y, Wang L, et al. Targeting a ceramide double bond improves insulin resistance and hepatic steatosis. Science (New York, NY). (2019). 365(6451). doi: 10.1126/science.aav3722

71. Yki-Järvinen H. Ceramides: a cause of insulin resistance in nonalcoholic fatty liver disease in both murine models and humans. Hepatology. (2020) 71:1499-501. doi: 10.1002/hep.31095

72. Holland WL, Brozinick JT, Wang LP, Hawkins ED, Sargent KM, Liu Y, et al. Inhibition of ceramide synthesis ameliorates glucocorticoid-, saturatedfat-, and obesity-induced insulin resistance. Cell Metab. (2007) 5:167-79. doi: 10.1016/j.cmet.2007.01.002

73. Razak Hady H, Błachnio-Zabielska AU, Szczerbiński Ł, Zabielski P, Imierska M, Dadan J, Kretowski AJ. Ceramide Content in Liver Increases Along with Insulin Resistance in Obese Patients. J Clin Med. (2019) 8. doi: 10.3390/jcm8122197

74. Margalit M, Shalev Z, Pappo O, Sklair-Levy M, Alper R, Gomori M, et al. Glucocerebroside ameliorates the metabolic syndrome in $\mathrm{OB} / \mathrm{OB}$ mice. $J$ Pharmacol Exp Ther. (2006) 319:105-10. doi: 10.1124/jpet.106.104950

75. Zigmond E, Zangen SW, Pappo O, Sklair-Levy M, Lalazar G, Zolotaryova L, et al. $\beta$-Glycosphingolipids improve glucose intolerance and hepatic steatosis of the Cohen diabetic rat. Am J Physiol Endocrinol Metab. (2009) 296:E72-8. doi: 10.1152/ajpendo.90634.2008

76. Zigmond E, Tayer-Shifman O, Lalazar G, Ben Ya'acov A, Zangen S, Shasha $\mathrm{D}$, et al. Beta-glycosphingolipids ameliorated non-alcoholic steatohepatitis in the Psammomys obesus model. Journal of Inflammation Research. (2014) 151. doi: 10.2147/JIR.S50508

77. Tagami S, Inokuchi Ji J-i, Kabayama K, Yoshimura H, Kitamura F, Uemura S, et al. Ganglioside GM3 participates in the pathological conditions of insulin resistance. J Biol Chem. (2002) 277:3085-92. doi: 10.1074/jbc.M103705200

78. Mallat Z, Tedgui A. Current perspective on the role of apoptosis in atherothrombotic disease. Circ Res. (2001) 88:998-1003. doi: 10.1161/hh1001.090571

79. Kobayashi K, Nagata E, Sasaki K, Harada-Shiba M, Kojo S, Kikuzaki H. Increase in secretory sphingomyelinase activity and specific ceramides in the aorta of apolipoprotein E knockout mice during aging. Biol Pharm Bull. (2013) 36:1192-6. doi: 10.1248/bpb.b13-00180

80. Ishimaru K, Yoshioka K, Kano K, Kurano M, Saigusa D, Aoki J, et al. Sphingosine kinase-2 prevents macrophage cholesterol accumulation and atherosclerosis by stimulating autophagic lipid degradation. Sci Rep. (2019) 9:18329. doi: 10.1038/s41598-019-54877-6

81. Laaksonen R, Ekroos K, Sysi-Aho M, Hilvo M, Vihervaara T, Kauhanen $\mathrm{D}$, et al. Plasma ceramides predict cardiovascular death in patients with stable coronary artery disease and acute coronary syndromes beyond LDLcholesterol. Eur Heart J. (2016) 37:1967-76. doi: 10.1093/eurheartj/ehw148

82. Meeusen JW, Donato LJ, Bryant SC, Baudhuin LM, Berger PB, Jaffe AS. Plasma ceramides a novel predictor of major adverse cardiovascular events after coronary angiography. Arterioscler Thromb Vasc Biol. (2018) 38:1933-9. doi: 10.1161/ATVBAHA.118.311199

83. Cheng JM, Suoniemi M, Kardys I, Vihervaara T, de Boer SPM, Akkerhuis $\mathrm{KM}$, et al. Plasma concentrations of molecular lipid species in relation to coronary plaque characteristics and cardiovascular outcome: Results of the ATHEROREMO-IVUS study. Atherosclerosis. (2015) 243:560-6. doi: 10.1016/j.atherosclerosis.2015.10.022

84. Wang DD, Toledo E, Hruby A, Rosner BA, Willett WC, Sun Q, et al. Plasma ceramides, mediterranean diet, and incident cardiovascular disease in the PREDIMED trial (prevención con dieta mediterránea). Circulation. (2017) 135:2028-40. doi: 10.1161/CIRCULATIONAHA.116.024261

85. Lu YC, Yeh WC, Ohashi PS. LPS/TLR4 signal transduction pathway. Cytokine. (2008) 42:145-151. doi: 10.1016/j.cyto.2008.01.006

86. Mobarak E, Håversen L, Manna M, Rutberg M, Levin M, Perkins R, et al. Glucosylceramide modifies the LPS-induced inflammatory response in macrophages and the orientation of the LPS/TLR4 complex in silico. Sci Rep. (2018) 8:13600. doi: 10.1038/s41598-018-31926-0

87. Arai T, Bhunia AK, Chatterjee S, Bulkley GB. Lactosylceramide stimulates human neutrophils to upregulate Mac-1 adhere to endothelium, and generate reactive oxygen metabolites in vitro. Circ Res. (1998) 82:540-7. doi: 10.1161/01.RES.82.5.540

88. Chatterjee S. Oxidized low density lipoproteins and lactosylceramide both stimulate the expression of proliferating cell nuclear antigen and the proliferation of aortic smooth muscle cells. Indian Journal of Biochemistry and Biophysics. (1997) 34:56-60.

89. Edsfeldt A, Dunér P, Stahlman M, Mollet IG, Asciutto G, Grufman $\mathrm{H}$, et al. Sphingolipids contribute to human atherosclerotic plaque inflammation. Arterioscler Thromb Vasc Biol. (2016) 36:1132-40. doi: 10.1161/ATVBAHA.116.305675

90. Gong N, Wei H, Chowdhury SH, Chatterjee S. Lactosylceramide recruits PKCalpha/epsilon and phospholipase A2 to stimulate PECAM-1 expression in human monocytes and adhesion to endothelial cells. Proc Natl Acad Sci U $S$ A. (2004) 101:6490-5. doi: 10.1073/pnas.0308684101

91. Chatterjee S, Bedja D, Mishra S, Amuzie C, Avolio A, Kass DA, et al. Inhibition of glycosphingolipid synthesis ameliorates atherosclerosis and arterial stiffness in apolipoprotein E-/- mice and rabbits fed a high-fat and -cholesterol diet. Circulation. (2014) 129:2403-13. doi: 10.1161/CIRCULATIONAHA.113.007559

92. Prokazova NV, Mikhailenko IA, Bergelson LD. Ganglioside GM3 stimulates the uptake and processing of low density lipoproteins by macrophages. Biochem Biophys Res Commun. (1991) 177:582-7. doi: 10.1016/0006-291X(91)92023-D

93. Stith JL, Velazquez FN, Obeid LM. Advances in determining signaling mechanisms of ceramide and role in disease. J Lipid Res. (2019) 60:913-8. doi: 10.1194/jlr.S092874

94. Haimovitz-Friedman A, Kolesnick RN, Fuks Z. Ceramide signaling in apoptosis. Br Med Bull. (1997) 53:539-53. doi: 10.1093/oxfordjournals.bmb.a011629

95. Hakomori S. Structure, organization, and function of glycosphingolipids in membrane. Curr Opin Hematol. (2003) 10:16-24. doi: 10.1097/00062752-200301000-00004

96. Zhang T, Waard AAd, Wuhrer M, Spaapen RM. The role of glycosphingolipids in immune cell functions. Front Immunol. (2019) 10:90. doi: 10.3389/fimmu.2019.00090

97. Iwabuchi K. Involvement of glycosphingolipid-enriched lipid rafts in inflammatory responses. Front Biosci. (Landmark edition). (2015) 20:325-34. doi: $10.2741 / 4312$

98. Chatterjee S, Balram A, Li W. Convergence: Lactosylceramide-Centric Signaling Pathways Induce Inflammation, Oxidative Stress, and Other Phenotypic Outcomes. Int J Mol Sci. (2021) 22. doi: 10.3390/ijms22041816 
99. Walters MJ, Wrenn SP. Effect of Sphingomyelinase-mediated generation of ceramide on aggregation of low-density lipoprotein. Langmuir. (2008) 24:9642-7. doi: 10.1021/la800714w

100. Walters MJ, Wrenn SP. Mechanistic roles of lipoprotein lipase and sphingomyelinase in low density lipoprotein aggregation. J Colloid Interface Sci. (2011) 363:268-74. doi: 10.1016/j.jcis.2011.07.072

101. Schissel SL, Tweedie-Hardman J, Rapp JH, Graham G, Williams KJ, Tabas I. Rabbit aorta and human atherosclerotic lesions hydrolyze the sphingomyelin of retained low-density lipoprotein: Proposed role for arterial-wall sphingomyelinase in subendothelial retention and aggregation of atherogenic lipoproteins. J Clin Invest. (1996) 98:1455-64. doi: 10.1172/JCI118934

102. Li W, Yang X, Xing S, Bian F, Yao W, Bai X, et al. Endogenous ceramide contributes to the transcytosis of oxldl across endothelial cells and promotes its subendothelial retention in vascular wall. Oxid Med Cell Longev. (2014) 2014. doi: 10.1155/2014/823071

103. Gao D, Pararasa C, Dunston CR, Bailey CJ, Griffiths HR. Palmitate promotes monocyte atherogenicity via de novo ceramide synthesis. Free Radic Biol Med. (2012) 53:796-806. doi: 10.1016/j.freeradbiomed.2012.05.026

104. Chaurasia B, Kaddai VA, Lancaster GI, Henstridge DC, Sriram S, Galam DL, et al. Adipocyte Ceramides Regulate Subcutaneous Adipose Browning, Inflammation, and Metabolism. Cell Metab. (2016) 24:820-34. doi: 10.1016/j.cmet.2016.10.002

105. Summers SA, Chaurasia B, Holland WL. Metabolic Messengers: ceramides. Nat Metab. (2019) 1:1051-8. doi: 10.1038/s42255-019-0134-8

106. Novgorodov SA, Riley CL, Yu J, Keffler JA, Clarke CJ, Van Laer AO, Baicu CF, et al. Lactosylceramide contributes to mitochondrial dysfunction in diabetes. J Lipid Res. (2016) 57:546-62. doi: 10.1194/jlr.M060061

107. Rambold AS, Pearce EL. Mitochondrial dynamics at the interface of immune cell metabolism and function. Trends Immunol. (2018) 39:6-18. doi: 10.1016/j.it.2017.08.006

108. Bhunia AK, Han H, Snowden A, Chatterjee S. Redox-regulated signaling by lactosylceramide in the proliferation of human aortic smooth muscle cells. $J$ Biol Chem. (1997) 272:15642-9. doi: 10.1074/jbc.272.25.15642

109. Garner B, Priestman DA, Stocker R, Harvey DJ, Butters TD, Platt FM. Increased glycosphingolipid levels in serum and aortae of apolipoprotein E gene knockout mice. J Lipid Res. (2002) 43:205-14. doi: 10.1016/S0022-2275(20)30162-0

110. Castoldi A, Monteiro LB, van Teijlingen Bakker N, Sanin DE, Rana N, Corrado $M$, et al. Triacylglycerol synthesis enhances macrophage inflammatory function. Nat Commun. (2020). 11:4107. doi: 10.1038/s41467-020-17881-3

111. Mishra S, Bedja D, Amuzie C, Avolio A, Chatterjee S. Prevention of cardiac hypertrophy by the use of a glycosphingolipid synthesis inhibitor in ApoE-/- mice. Biochem Biophys Res Commun. (2015) 46:159-64. doi: 10.1016/j.bbrc.2015.07.159

112. Fiorelli S, Anesi A, Porro B, Cosentino N, Werba JP, Di Minno A, et al. Lipidomics analysis of monocytes from patients with acute myocardial infarction reveals lactosylceramide as a new player in monocyte migration. Faseb j. (2021). 35:e21494. doi: 10.1096/fj.202001872RRR

113. Bhunia AK, Arai T, Bulkley G, Chatterjee S. Lactosylceramide mediates tumor necrosis factor-alpha-induced intercellular adhesion molecule1 (ICAM-1) expression and the adhesion of neutrophil in human umbilical vein endothelial cells. J Biol Chem. (1998) 273:34349-57. doi: 10.1074/jbc.273.51.34349

114. Tan AH, Sanny A, Ng SW, Ho YS, Basri N, Lee AP, et al. Excessive interferon$\alpha$ signaling in autoimmunity alters glycosphingolipid processing in B cells. $J$ Autoimmun. (2018) 89:53-62. doi: 10.1016/j.jaut.2017.11.004

115. Spijkers LJA, van den Akker RFP, Janssen BJA, Debets JJ, De Mey JGR, Stroes ESG, et al. Hypertension is associated with marked alterations in sphingolipid biology: a potential role for ceramide. PLOS ONE. (2011) 6:e21817-e21817. doi: 10.1371/journal.pone.0021817

116. Guyton JR, Klemp KF. Development of the Lipid-Rich Core in Human Atherosclerosis. Arterioscler Thromb Vasc Biol. (1996) 16:4-11. doi: 10.1161/01.ATV.16.1.4

117. Nicholls M. Plasma ceramides and cardiac risk. Eur Heart J. (2017) 38:135960. doi: 10.1093/eurheartj/ehx205

118. Buie JNJ, Hammad SM, Nietert PJ, Magwood G, Adams RJ, Bonilha L, et al. Differences in plasma levels of long chain and very long chain ceramides between African Americans and whites: An observational study. PLoS ONE. (2019) 14:e0216213-e0216213. doi: 10.1371/journal.pone.0216213

119. Huynh K, Barlow CK, Jayawardana KS, Weir JM, Mellett NA, Cinel M, et al. High-Throughput Plasma Lipidomics: Detailed Mapping of the Associations with Cardiometabolic Risk Factors. Cell Chemical Biology. (2019) 26:7184.e4. doi: 10.1016/j.chembiol.2018.10.008

120. Lemaitre RN Yu C, Hoofnagle A, Hari N, Jensen PN, Fretts AM, et al. Circulating sphingolipids, insulin, HOMA-IR, and HOMA-B: the strong heart family study. Diabetes. (2018) 67:1663-72. doi: 10.2337/db17-1449

121. Kim M, Jung S, Lee SH, Lee JH. Association between arterial stiffness and serum L-octanoylcarnitine and lactosylceramide in overweight middleaged subjects: 3-year follow-up study. PLOS ONE. (2015) 10:e0119519. doi: 10.1371/journal.pone.0119519

122. Meikle PJ, Christopher MJ. Lipidomics is providing new insight into the metabolic syndrome and its sequelae. Curr Opin Lipidol. (2011) 22:210-5. doi: 10.1097/MOL.0b013e3283453dbe

123. Ramakrishanan N, Denna T, Devaraj S, Adams-Huet B, Jialal I. Exploratory lipidomics in patients with nascent Metabolic Syndrome. J Diabetes Complications. (2018) 32:791-4. doi: 10.1016/j.jdiacomp.2018.05.014

124. Gong Ll, Yang S, Zhang W, Han Ff, Lv Yl, Xuan Ll, et al. Discovery of metabolite profiles of metabolic syndrome using untargeted and targeted LC-MS based lipidomics approach. J Pharm Biomed Anal. (2020). 177:112848-112848. doi: 10.1016/j.jpba.2019.112848

125. Yin X, Willinger CM, Keefe J, Liu J, Fernández-Ortiz A, Ibáñez B, et al Lipidomic profiling identifies signatures of metabolic risk. EBioMedicine. (2020) 51:102520-102520. doi: 10.1016/j.ebiom.2019.10.046

126. Luukkonen PK, Zhou Y, Sädevirta S, Leivonen M, Arola J, Orešič M, et al. Hepatic ceramides dissociate steatosis and insulin resistance in patients with non-alcoholic fatty liver disease. J Hepatol. (2016) 64:1167-75. doi: 10.1016/j.jhep.2016.01.002

127. Wigger L, Cruciani-Guglielmacci C, Nicolas A, Denom J, Fernandez N, Fumeron F, et al. Plasma Dihydroceramides Are Diabetes Susceptibility Biomarker Candidates in Mice and Humans. Cell Rep. (2017) 18:2269-79. doi: 10.1016/j.celrep.2017.02.019

128. Chapman MJ, Orsoni A, Tan R, Mellett NA, Nguyen A, Robillard P, et al. LDL subclass lipidomics in atherogenic dyslipidemia: effect of statin therapy on bioactive lipids and dense LDL. J Lipid Res. (2020) 61. doi: 10.1194/jlr.P119000543

129. Hyötyläinen T, Orešič M. Optimizing the lipidomics workflow for clinical studies-practical considerations. Anal Bioanal Chem. (2015) 407:4973-93.

130. Osei K, Gaillard T. Disparities in cardiovascular disease and type 2 diabetes risk factors in blacks and whites: dissecting racial paradox of metabolic syndrome. Front Endocrinol. (2017) 8:204. doi: 10.3389/fendo.2017. 00204

131. Torretta E, Barbacini P, Al-Daghri NM, Gelfi C. Sphingolipids in obesity and correlated co-morbidities: the contribution of gender, age and environment. Int J Mol Sci. (2019) 20:5901. doi: 10.3390/ijms20235901

132. Gaillard TR. The metabolic syndrome and its components in AfricanAmerican women: emerging trends and implications. Front Endocrinol (Lausanne). (2017) 8:383. doi: 10.3389/fendo.2017.00383

Conflict of Interest: The authors declare that the research was conducted in the absence of any commercial or financial relationships that could be construed as a potential conflict of interest.

Publisher's Note: All claims expressed in this article are solely those of the authors and do not necessarily represent those of their affiliated organizations, or those of the publisher, the editors and the reviewers. Any product that may be evaluated in this article, or claim that may be made by its manufacturer, is not guaranteed or endorsed by the publisher.

Copyright (C) 2022 Berkowitz, Cabrera-Reyes, Salazar, Ryff, Coe and Rigotti. This is an open-access article distributed under the terms of the Creative Commons Attribution License (CC BY). The use, distribution or reproduction in other forums is permitted, provided the original author(s) and the copyright owner(s) are credited and that the original publication in this journal is cited, in accordance with accepted academic practice. No use, distribution or reproduction is permitted which does not comply with these terms. 